\title{
Protective Effects of Combined Therapy of Rutin with Silymarin on Experimentally- Induced Diabetic Neuropathy in Rats
}

\author{
Maher M. Al-Enazi1,2 \\ ${ }^{1}$ Voice Rector for Academic Affairs, Aljouf University, Sakaka, Saudi Arabia \\ ${ }^{2}$ Department of Medical Laboratory Sciences, College of Applied Medical Sciences, Salman bin Abdulaziz \\ University, Al-Kharj, Saudi Arabia \\ Email: maherelenazi210@gmail.com
}

Received 18 June 2014; revised 20 July 2014; accepted 8 August 2014

Copyright (C) 2014 by author and Scientific Research Publishing Inc.

This work is licensed under the Creative Commons Attribution International License (CC BY). http://creativecommons.org/licenses/by/4.0/

(c) (i) Open Access

\section{Abstract}

The management of diabetic neuropathy (DN) is still a challenge for physicians. Hyperglycemia induced oxidative stress involves in the development of diabetic neuropathy, which could be reversed by supplementation of antioxidants. In the present study, it has targeted the oxidative stress mediated nerve damage in DN by using combined therapy of rutin (RT) and silymarin (SM). Diabetes was induced by single streptozotocin (STZ, $65 \mathrm{mg} / \mathrm{kg}$ i.p.) injection. The diabetic rats were treated daily with RT $(100 \mathrm{mg} / \mathrm{kg})$, SM $(60 \mathrm{mg} / \mathrm{kg})$ and RT $(50 \mathrm{mg} / \mathrm{kg})+S M(30 \mathrm{mg} / \mathrm{kg})$ for 6 consecutive weeks. Pain-related behavior tests were performed including tail flick, paw-pressure analgesia and Rota-rod treadmill performance. Serum glucose, insulin, tumor necrosis factor- $\alpha$ (TNF- $\alpha$ ), interleukine-6 (IL-6) and interleukine-1 $\beta$ (IL- $\beta$ ) levels were estimated. Thiobarbituric acid reactive substances (TBARS), reduced glutathione (GSH) levels and enzymatic activities of superoxide dismutase (SOD), catalase (CAT), glutathione-S-transferase (GST), glutathione reductase (GR) and glutathione peroxidase (GPx) were measured. Diabetic rats that developed neuropathy were revealed by decreased tail-flick latency, paw-withdrawal latency and motor coordination. RT $(100 \mathrm{mg} / \mathrm{kg} /$ day $)$ and SM $(60 \mathrm{mg} / \mathrm{kg} /$ day $)$ dosed to diabetic rats, ameliorated hyperalgesia, analgesia and led to improved motor coordination. However, the combined therapy of RT (50 $\mathrm{mg} / \mathrm{kg} / \mathrm{day})$ with SM $(30 \mathrm{mg} / \mathrm{kg} / \mathrm{day})$ showed more significant effects in these parameters. STZ significantly increased TBARS and decreased GSH levels in sciatic nerve whereas combined therapy of RT and SM produced higher significant protection compared to individual. Similarly, combined therapy showed more significant amelioration in decreased levels of SOD, CAT, GST, GS and GPx activities in sciatic nerve of diabetic rats. Present results concluded that the combined therapy of phenolic compounds such as RT and SM had higher protective effects than their individual supplementations against DM. 


\section{Keywords}

\section{Rutin, Silymarin, Diabetic Neuropathy, Oxidative Stress, Inflammation}

\section{Introduction}

Numerous epidemiological studies show that the number of diabetic people is increasing due to population growth, aging, urbanization and high prevalence of obesity and physical inactivity [1]. Diabetes is associated with high risk of microvascular complications such as retinopathy, nephropathy and neuropathy [2]. DN occurs about $15 \%-25 \%$ in type- 1 and $30 \%-40 \%$ in type- 2 diabetic patients, causing disabilities and a high mortality rate [3]. Neuropathic pain is defined as a form of chronic pain that results from damage or abnormal function of central or peripheral nervous system [4]. The patients suffering from neuropathic pain frequently report sensory abnormalities such as burning sensations, hyperalgesia, allodynia and dysesthesia [5]. It can also alter the patient's quality of life by interfering with emotional well-being [6].

Experimental studies in diabetic rodent models have demonstrated that DN is the result of a complex network of interrelated vascular [7], metabolic [8] and neurotrophic defects [9] which culminate in electrophysiological deficits, abnormal sensory perception and progressive damage and loss of unmyelinated and myelinated nerve fibers [10]. Metabolic changes that may be involved in the pathogenesis of DN include polyol pathwayflux, increased oxidative stress via glucose autoxidation and the subsequent formation of advanced glycation end products (AGEs), altered eicosanoid metabolism, activation of nuclear enzyme poly (ADP-ribose) polymerase and decreased antioxidant defense [11].

Oxidative stress is believed to be a biochemical trigger for sciatic nerve dysfunction and reduced endoneurial blood flow in diabetic rats [12]. In this regards, the potential sources of reactive oxygen species (ROS) including endothelial NADPH oxidase, xanthine oxidase, nitric oxide synthase and mitochondrial respiratory chain inefficiency are more notable [13]. Furthermore, diabetes is linked with reduced activity of GST, GPx, GR, Cu-Zn superoxide dismutase and lower levels of glutathione [14]-[16]. Opposite to this, diabetes causes increase in the lipid peroxidation (LPO) products such as MDA or conjugated dienes in sciatic nerves [17]. Enhanced oxidative stress consecutively activates nuclear factor kappa B (NF-jB), which up-regulates genes such as cytokines, adhesion molecules, endothelin-1 and tissue factor [18]. Although DN is traditionally considered a non-immune disease, accumulating evidence now indicates that immunologic and inflammatory mechanisms play a significant role in its development and progression [19] [20]. TNF- $\alpha$ has a major role in the immune system and it increases in type 1 diabetic patients with DN and also shows independent correlation between interleukins and DN [21].

Epidemiological studies have shown that many phytonutrients of fruits and vegetables might protect the human body against damage by ROS. The consumption of natural antioxidant phytochemicals was reported to have potential health benefits [22]. Flavonoids are known to have powerful antioxidant activities that could play a protective role in oxidative stress-mediated diseases including diabetes, inflammation, hepatotoxicity and cardiovascular diseases [23]-[26]. Rutin (quercetin-3-rutinosid or vitamin-P) is a flavonol glycoside, which is comprised of the flavonol quercetin and the disaccharide rutinose and it is known to have pharmacological activity such as lowering blood pressure and capillary reinforcement and as an anti-inflammatory [27] [28]. Moreover, rutin has inhibitory effects against membrane lipid peroxidation [23]. Silymarin, an extract from the seeds of the milk thistle plant, Silybummarianum, has been used for centuries against liver diseases. Silymarin is a mixture of seven flavonolignans: 1) silybin-A, 2) silybin-B, 3) isosilybin-A, 4) isosilybin-B, 5) silychristin, 6) silydianin, and 7) isosilychristin and one flavonoid named taxifolin. It is experimentally evidenced that silymarin has antioxidant, immunomodulatory, anti-fibrotic, anti-proliferative and anti-viral activities although its mechanism of action is incompletely understood till date [29]-[31]. When multiple antioxidants are used in combination, they protect against vulnerability to other agents and synergistically potentiate their antioxidant properties [32]. These synergistically potentiated antioxidant effects of agents contribute to the improvement of cognitive function. Thus it was found worth to experimentally examine the neuroprotective potential of combined therapy of RT and SM supplementation on the diabetic-induced changes in development of behavioral and biochemical deficits in rats. 


\section{Materials and Methods}

\subsection{Animals}

Wistar male albino rats, roughly the same age of 12 - 13 weeks and weighing 250 - 280 g were received from the Experimental Animal Care Center (College of Pharmacy, King Saud University, Riyadh, Saudi Arabia). They were maintained under controlled conditions of temperature $\left(22^{\circ} \mathrm{C} \pm 1^{\circ} \mathrm{C}\right)$, humidity $(50 \%-55 \%)$ and light (12 h light/dark cycles) and were provided with Purina chow (Grain Silos \& Flour Mills Organization, Riyadh, Saudi Arabia) and water ad libitum. All procedures including anesthesia were conducted in accordance with the National Institute of Health Guide for the Care and Use of Laboratory Animals, Institute for Laboratory Animal Research (NIH Publications No. 80-23; 1996, USA) and the Ethical Guidelines of the Experimental Animal Care Center, College of Pharmacy, King Saud University, Riyadh, Saudi Arabia. The ethical clearance has taken form Experimental Animal Care Center.

\subsection{Diabetes Induction}

Diabetes was induced in overnight fasted rats by a single intraperitoneal injection of STZ (SIGMA Chemicals, USA) at a dose of $60 \mathrm{mg} / \mathrm{kg}$ body weight freshly dissolved in $0.1 \mathrm{~mol} / \mathrm{L}$ citrate buffer, $\mathrm{pH} 4.5$. Control rats as vehicle received equal volume of citrate buffer. The animals with fasting blood glucose values more than 250 $\mathrm{mg} / \mathrm{dl}$ after $72 \mathrm{~h}$ of STZ injection were considered diabetic and included in the study.

\subsection{Study Design}

Six normal healthy rats were used in control group (vehicle) and the STZ-induced diabetic rats were randomly divided as, diabetic (STZ), RT (100 mg/kg/day) treated to diabetic rats (RT100 + STZ), SM $(60 \mathrm{mg} / \mathrm{kg} / \mathrm{day})$ treated to diabetic rats (SM60 + STZ) and RT + SM (50 and $30 \mathrm{mg} / \mathrm{kg} /$ day respectively) treated to diabetic rats $($ RT50 + SM30 + STZ). Vehicle and drug treatment were started three weeks after the diabetes induction and continued for six consecutive weeks by orally (Gavage). Behavioral assessments including mechanical hyperalgesia test, tail flick test and Rot rod treadmill test were under taken before and after treatments. At the end of the experiment, rats were fasted overnight for $12 \mathrm{~h}$ and blood samples were obtained by cardiac puncture under ether anesthesia. Animals were then sacrificed by cervical dislocation and sciatic nerve tissues were rapidly removed and dipped in liquid nitrogen for a minute and kept in deep freezer at $-80^{\circ} \mathrm{C}$ till analysis of TBARS, GSH, SOD, CAT, GST, GR and GPx activities.

\subsection{Paw Pressure Withdrawal Test}

The method described by Sugimoto et al. [33], was used with slight modifications. In summary, twenty four hours after the lost day of treatment, paw pressure thresholds were recorded with the paw pressure analgesia meter (MK-20D Analgesic meter, Muromachi KIKAI CO. Ltd., Japan). A constantly increasing pressure stimulus was applied to the dorsal surface of the rat hind paw while the animal was gently restrained under a soft towel to avoid tissue damage, a cutoff of $400 \mathrm{mmHg}$ was used. The pressure was increased until the animal withdrew the paw, squeaked or struggled. One measurement per paw was performed with an interval of longer than 15 minutes between measurements; for each animal, the results for the 2 paws were averaged for use in statistical analysis.

\subsection{Tail Flick Test}

The method described by Sugimoto et al. [33], was used with slight modifications. Acute nociception was induced by using a tail flick apparatus (Tail Flick model DS 20 Sorrel Apelex, France). Briefly, each rat placed in a restrainer and the tail flick latency was determined by focusing the intensity controlled beam of light on the distal last $2 \mathrm{~cm}$ of the animal's tail and recording the time taken to remove the tail from the noxious thermal stimulus. For each animal, 2 to 3 recordings were made at an interval of 15 minutes; the mean value was used for statistical analysis.

\subsection{Measurement of Motor Coordination (Rota Rod Treadmill Test)}

The method described by Kamboj et al. [34], was used with slight modifications. The Rota-Rod Treadmill for 
rats and mice (Model MK-670, Muromachi Kikai Co, Ltd., Tokyo, Japan) was used. Animals were initially trained to maintain themselves on the rotating rod for more than $2 \mathrm{~min}$. In test trials, the time (in seconds) that trained rats could stay on the rod, rotating at $20 \mathrm{rpm}$, with a cut off at $60 \mathrm{~min}$ was measured. Rats were placed on the rotating rod for two trials each.

\subsection{Serum Analysis for What?}

Serum fasting glucose levels were estimated by using the commercially available kit (RANDOX Laboratories Ltd., UK) and insulin levels were measured by using enzyme immunoassay (ELISA) kit (DRG, Germany). The serum level of TNF- $\alpha$, IL- $1 \beta$ and IL- 6 were determined using commercially available ELISA kits (R and D systems, Minneapolis, USA).

\subsection{Tissue Homogenate for What Measurements?}

Sciatic nerve samples were homogenized in $50 \mathrm{mM}$ phosphate buffered saline (pH 7.4) by using a glass homogenizer (Omni International, Kennesaw, GA, USA). Half of the homogenates were centrifuged at $1000 \mathrm{~g}$ for 10 min at $4^{\circ} \mathrm{C}$ to separate nuclei and unbroken cells. The pellet was discarded and a portion of supernatant was again centrifuged at 12,000 g for 20 min to obtain post-mitochondrial supernatant. In homogenate, TBARS and GSH levels were estimated. In post-mitochondrial supernatant, SOD, CAT, GST, GR and GPx activities were measured.

\subsection{Estimation of TBARS Levels in Sciatic Nerve}

A TBARS assay kit (ZeptoMetrix) was used to measure the lipid peroxidation products, malondialdehyde (MDA) equivalents. One hundred microliters of homogenate was mixed with $2.5 \mathrm{ml}$ reaction buffer (provided by the kit) and heated at $95^{\circ} \mathrm{C}$ for $60 \mathrm{~min}$. After the mixture had cooled, the absorbance of the supernatant was measured at $532 \mathrm{~nm}$ using a spectrophotometer. The lipid peroxidation products are expressed in terms of nmoles MDA/mg protein using molar extinction coefficient of MDA-thiobarbituric chromophore $(1.56 \times$ $\left.10^{5} / \mathrm{M} / \mathrm{cm}\right)$.

\subsection{Estimations GSH Levels in Sciatic Nerve}

The GSH levels were measured using the method described by Sedlak and Lindsay [35]. Homogenate was mixed with $0.2 \mathrm{M}$ Tris buffer, $\mathrm{pH} 8.2$ and $0.1 \mathrm{~mL}$ of $0.01 \mathrm{M}$ Ellman's reagent, [5,5'-dithiobis-(2-nitro-benzoic acid)] (DTNB). Each sample tube was centrifuged at $3000 \mathrm{~g}$ at room temperature for $15 \mathrm{~min}$. The absorbance of the clear supernatants was measured using spectrophotometer at $412 \mathrm{~nm}$ in one centimeter quarts cells.

\subsection{Estimations of SOD Activity in Sciatic Nerve}

The activity of SOD in sciatic nerve was estimated using the method described by Kono [36], with the aid of nitrobluetetrazolium as the indicator. Superoxide anions are generated by the oxidation of hydroxylamine hydrochloride. The reduction of nitrobluetetrazolium to blue formazon mediated by superoxide anions was measured $560 \mathrm{~nm}$ under aerobic conditions. Addition of superoxide dismutase inhibits the reduction of nitrobluetetrazolium and the extent of inhibition is taken as a measure of enzyme activity. The SOD activity was expressed as units/mg protein.

\subsection{Estimation of CAT Activity in Sciatic Nerve}

The CAT activity was measured by the method of Aebi [37], using hydrogen peroxide as substrate in post-mitochondrial supernatant. The hydrogen peroxide decomposition by catalase was monitored on spectrophotometer (LKB-Pharmacia, Mark II, Ireland) by following the decrease in absorbance at $240 \mathrm{~nm}$. The activity of enzyme was expressed as units of decomposed/min/mg proteins by using molar extinction coefficient of $\mathrm{H}_{2} \mathrm{O}_{2}$ $(71 / \mathrm{M} / \mathrm{cm})$.

\subsection{Estimations of GST, GR and GPx Activities in Sciatic Nerve}

The enzymatic activities of GST, GR and GPx were determined by using ELISA kits (Cayman Inc, USA) in the 
post mitochondrial supernatant of colon homogenate on ELISA reader by following the manufacturer's instructions.

\subsection{Statistical Analysis}

All data were presented as the mean \pm Standard Deviation (SD). The data were evaluated by a one-way ANOVA using Graph Pad Prism program and the differences between means were assessed using Student NewmanKeuls. The differences were considered statistically significant at $\mathrm{P}<0.05$.

\section{Results}

\subsection{Effects on Glucose and Insulin Levels}

Mean plasma fasting glucose levels significantly $(\mathrm{P}<0.001)$ increased while insulin levels were decreased in STZ-induced diabetic rats. Treatments with RT and SM to diabetic animals for 6 consecutive weeks showed significant $(\mathrm{P}<0.05)$ decrease in fasting glucose and increase in insulin levels when compared to untreated diabetic rats. However, the combined treatment with RT and SM to diabetic rats showed more $(\mathrm{P}<0.01)$ protective effect on glucose and insulin levels (Figure 1).

\subsection{Effect on Mechanical Hyperalgesia}

In paw pressure analgesia test, vehicle-treated diabetic rats significantly decreased the paw withdrawal latency (PWL) compared to control animals. The diabetic group of animals treated with RT $(100 \mathrm{mg} / \mathrm{kg} / \mathrm{day})$ for 6 weeks could not significantly altered the PWL time (s) compared to untreated diabetic rats while SM (60 $\mathrm{mg} / \mathrm{kg} /$ day) treatment produce significant $(\mathrm{P}<0.05)$ increase in PWL time. The combine treatment of RT and SM $(50$ and $30 \mathrm{mg} / \mathrm{kg} /$ day respectively) to diabetic rats showed marked $(\mathrm{P}<0.01)$ increase in time of PWL compared untreated diabetic animals (Figure 2(a)).

\subsection{Effect on Tail Flick Latency (TFL)}

A significant decrease in TFL was observed after 9 weeks of STZ-induced diabetic rats compared to control animals. This decreased of TFL time in diabetic rats was significantly $(\mathrm{P}<0.01)$ reversed by SM treatment

Glucose

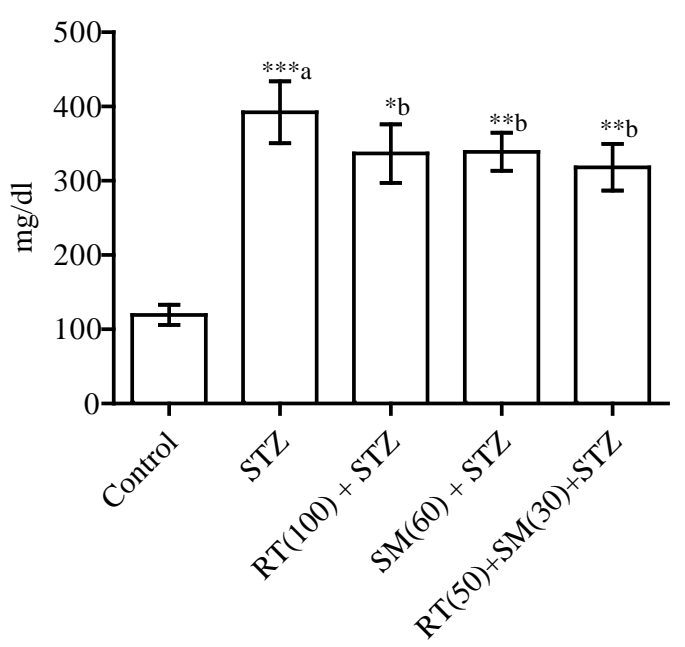

(a)
Insulin

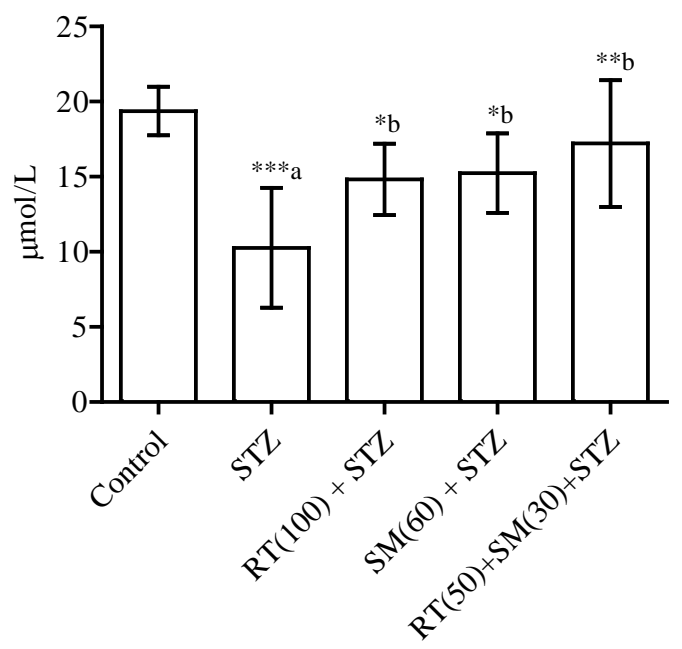

(b)

Figure 1. Effect of rutin (RT), silymarin (SM) and their combination on serum glucose and insulin levels of diabetic and non-diabetic animals. Data expressed as mean \pm SD $(n=6)$. One-way ANOVA and StudentNewman-Keuls multiple comparisons test was applied and the significance levels considered as ${ }^{*} \mathrm{P}<0.05,{ }^{* *} \mathrm{P}<$ 0.01 and ${ }^{* * *} \mathrm{P}<0.001$. a: significantly different from control group $(\mathrm{P}<0.05)$ and $\mathrm{b}$ : significantly different from STZ group. 
while RT could not show such increase in the TFL time. However, the combined therapy with RT and SM to diabetic rats revealed marked $(\mathrm{P}<0.01)$ increase in TFL compared to untreated diabetic animals (Figure 2(b)).

\subsection{Effect on Rota Rod Treadmill Performance}

Rota-rod treadmill performance of diabetic and non-diabetic animals is shown in Figure 2(c). The running performance on treadmill was significantly $(\mathrm{P}<0.001)$ decreased in diabetic animals compared to control rats. The distinct treatment of RT and SM to diabetic rats showed significant $\mathrm{P}<0.05$ and $\mathrm{P}<0.01$ enhancement in running performance when compared to untreated diabetic animals respectively. The combined treatment of RT and SM to diabetic rats enhanced more significantly $(\mathrm{P}<0.001)$ the running performance on treadmill compared to untreated diabetic animals.

\subsection{Effects on Pro-Inflammatory Cytokines}

Serum pro-inflammatory markers including TNF- $\alpha$, IL- $1 \beta$ and IL6 levels were markedly $(\mathrm{P}<0.001)$ increased in diabetic rats as compared to control animals. Treatments with RT and SM significantly $(\mathrm{P}<0.05)$ decreased

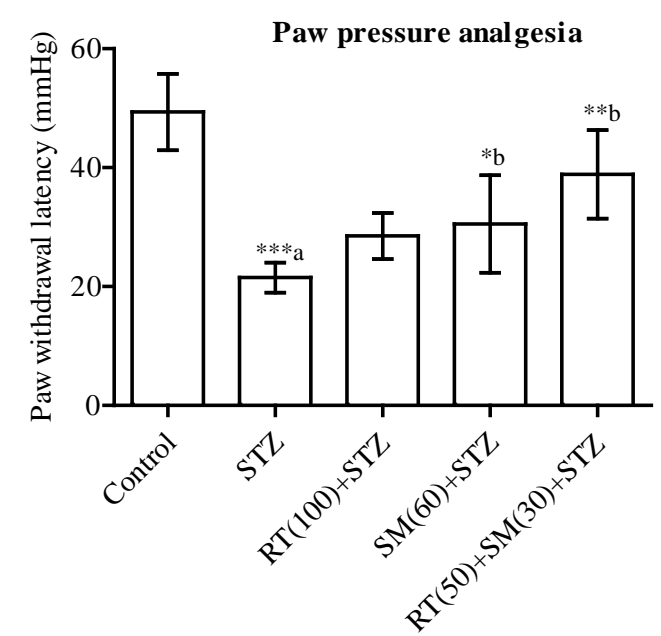

(a)

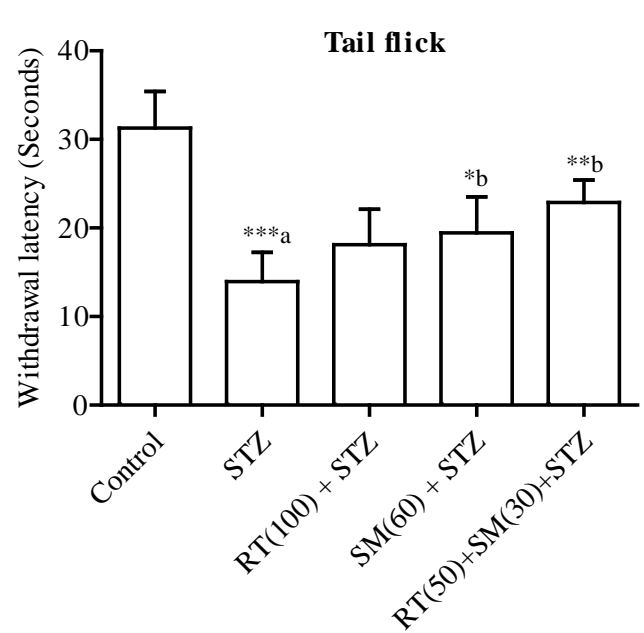

(b)

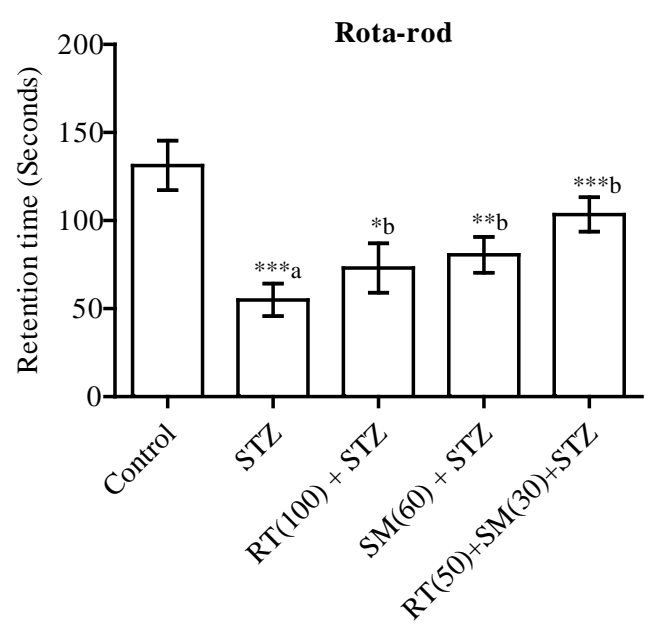

(c)

Figure 2. Effect of rutin (RT), silymarin (SM) and their combination on pain threshold in paw pressure analgesia, tail flick and Rota-rod treadmill performance of diabetic and non-diabetic animals. Data expressed as mean \pm SD $(n=6)$. One-way ANOVA and Student-Newman-Keuls multiple comparisons test was applied and the significance levels considered as ${ }^{*} \mathrm{P}<0.05,{ }^{* *} \mathrm{P}<0.01$ and ${ }^{* * *} \mathrm{P}<0.001$. a: significantly different from control group $(\mathrm{P}<0.05)$ and $\mathrm{b}$ : significantly different from STZ group. 
the TNF- $\alpha$ and IL- $1 \beta$ values in diabetic rats compared the untreated diabetic animals. The IL-6 levels significantly $(\mathrm{P}<0.01)$ inhibited after SM treatment while the RT treatment did not altered the levels significantly as compared untreated diabetic rats. Comparable to these individual treatment groups the combined therapy of RT and SM showed more significant effect on TNF- $\alpha(\mathrm{P}<0.01)$, IL-1 $\beta(\mathrm{P}<0.001)$ and IL-6 $(\mathrm{P}<0.001)$ levels when compared to untreated diabetic groups respectively (Figure 3).

\subsection{Effect on Lipid Peroxidation Bio-Markers}

Lipid peroxidation (LPD) bio-markers such as TBARS levels showed significantly ( $\mathrm{P}<0.001$ ) increased in sciatic nerves of diabetic rats while GSH levels decreased significantly $(\mathrm{P}<0.001)$ compared to control animals respectively. Treatments with RT and SM to diabetic rats for six weeks markedly reduced the TBARS levels and increased the GSH values compared STZ group. However, the combined treatment with RT and SM to diabetic rats showed more significant $(\mathrm{P}<0.001)$ effect on diabetic-induced LPD bio-markers when compared to untreated diabetic rats (Figure 4).

TNF-alpha

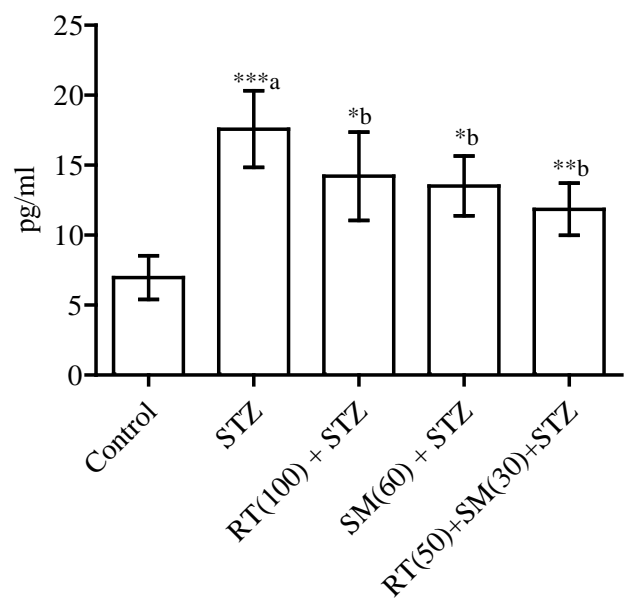

(a)
IL-1 $\beta$

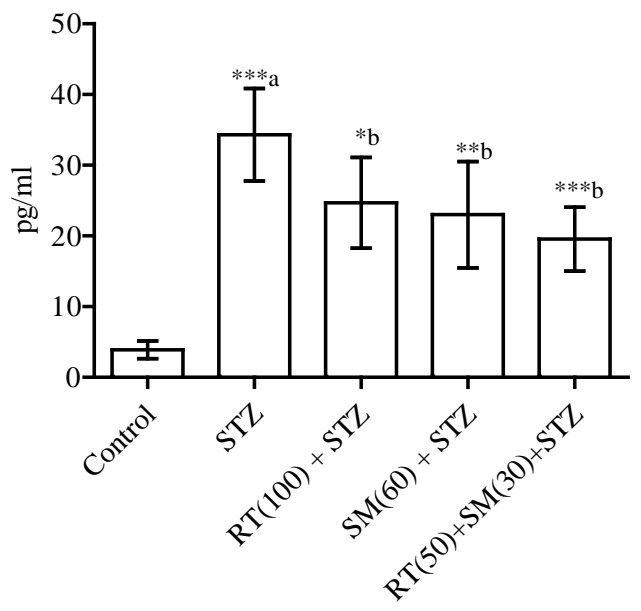

(b)

IL-6

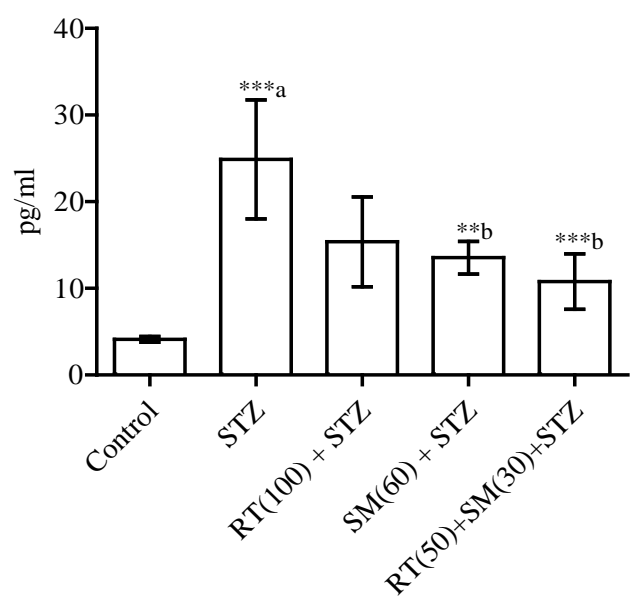

(c)

Figure 3. Effect of rutin (RT), silymarin (SM) and their combination on serum TNF- $\alpha$, IL- $1 \beta$ and IL-6 levels of diabetic and non-diabetic rats. Data expressed as mean \pm SD $(n=6)$. One-way ANOVA and Student-Newman-Keuls multiple comparisons test was applied and the significance levels considered as ${ }^{*} \mathrm{P}<0.05,{ }^{* *} \mathrm{P}<0.01$ and ${ }^{* * *} \mathrm{P}<0.001$. a: significantly different from control group $(\mathrm{P}<0.05)$ and $\mathrm{b}$ : significantly different from STZ group. 


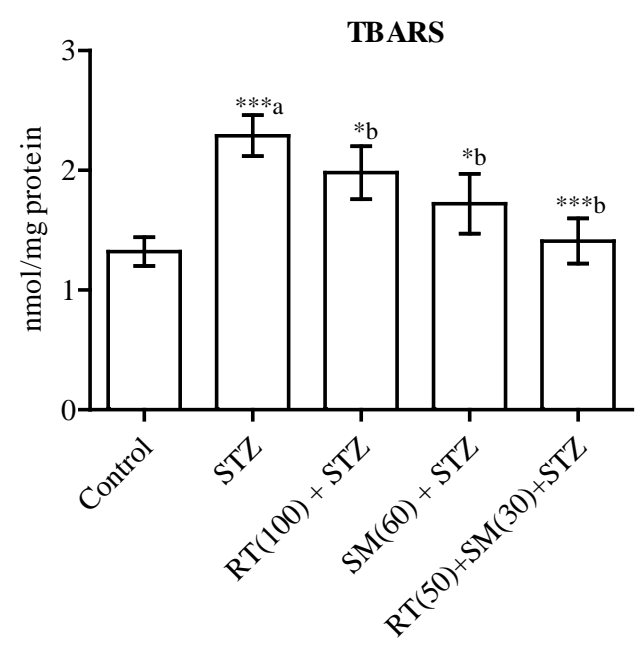

(a)

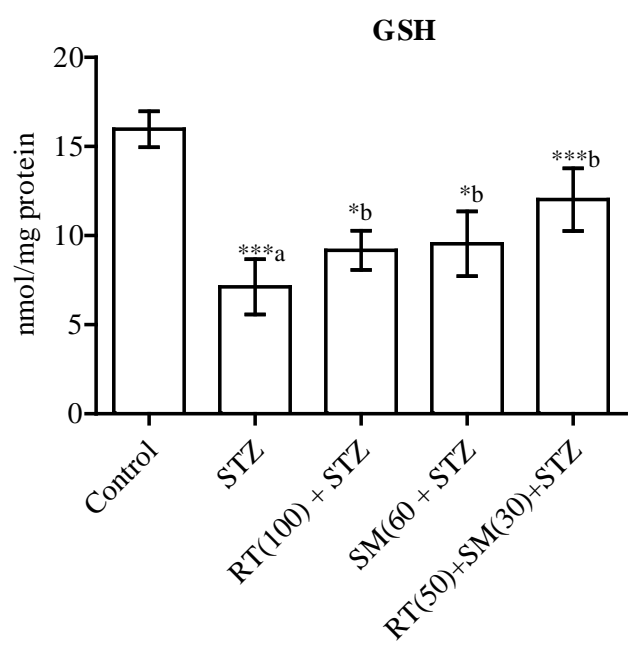

(b)

Figure 4. Effect of rutin (RT), silymarin (SM) and their combination on TBARS and GSH levels in sciatic nerve of diabetic and non-diabetic rats. Data expressed as mean \pm SD $(n=6)$. One-way ANOVA and Student-Newman-Keuls multiple comparisons test was applied and the significance levels considered as ${ }^{*} \mathrm{P}<0.05,{ }^{* *} \mathrm{P}<0.01$ and ${ }^{* * *} \mathrm{P}<0.001$. a: significantly different from control group $(\mathrm{P}<0.05)$ and $\mathrm{b}$ : significantly different from STZ group.

\subsection{Effects on Enzymatic Activities}

The oxidative enzymes including SOD, CAT, GST, GR and GPx activities significantly $(\mathrm{P}<0.001)$ inhibited in diabetic rats compared to control animals. The individual treatment of RT and SM to diabetic animals markedly enhanced these activities compared untreated diabetic animals. The combined therapy of RT and SM to diabetic rats revealed more significant $(\mathrm{P}<0.001)$ effect on inhibited activities of SOD, CAT, GST, GR and GPx than individual supplementation of these compounds (Figure 5).

\section{Discussion}

Diabetic neuropathic pain is one of the most common diabetic complications that approximately occur in half of the diabetic patients with symptoms of spontaneous pain, allodynia and hyperalgesia [38]. Experimentally induced diabetes by STZ is a well-documented animal model to explore behavioral and pharmacologic changes associated with DN [34]. Thermal sensitivity assessment in diabetic rats and mice was done using a number of behavioral tests, like tail flick, and hot-plate tests. Both thermal hyper- and hypo-algesia have been described in STZ-diabetic rats with short-term (2 - 8 weeks) diabetes [19]-[39]. Behavioral methods to test mechanical hyper- and hypo-algesia in experimental studies include mechanical withdrawal thresholds in diabetic rodents models assessed by paw (rats) and tail (mouse) pressure Randall-Selitto test or with a von Frey aesthesiometer and rigid von Frey filaments [40]. A decrease of the pressure withdrawal threshold by $30 \%-40 \%$ after 3 weeks of STZ-diabetes was reported by Romanovsky et al. [41]. Increased nociceptor activity and sensitivity during hyperglycemic hypoxia could be a mechanism or e.g. burning pain attacks in painful neuropathy [42]. In the present study, in diabetic rats, the tail withdrawal latency was significantly shorter than that observed in control animals, indicating development of thermal hyperalgesia. This was accompanied by decreased motor coordination as assessed by performance on Rota-rod treadmill. Most of the phenolic compounds are known to have anti-inflammatory, analgesic and also have anti-nociceptive properties [34] [43] [44]. This may be because of RT and SM combined treatments to diabetic rats for 6 consecutive weeks showed more significant improvement in TFL and PWL rate compared to individual treatment groups. Our findings are agreement with earlier reports that that combined supplementation of phenolic compounds have more potentials than individual treatment [45] [46].

Hyperglycemia is known to be one of the vital factors that can induce expression of inflammatory biomarkers during diabetes via oxidative stress pathways and associated rise in inflammatory path to induce neural cells death and dysfunction [47] [48]. Present findings obviously show the association between inflammation and the development of DN while the levels of pro-inflammatory biomarkers such as TNF- $\alpha$, Il- $1 \beta$ and IL-6 were 

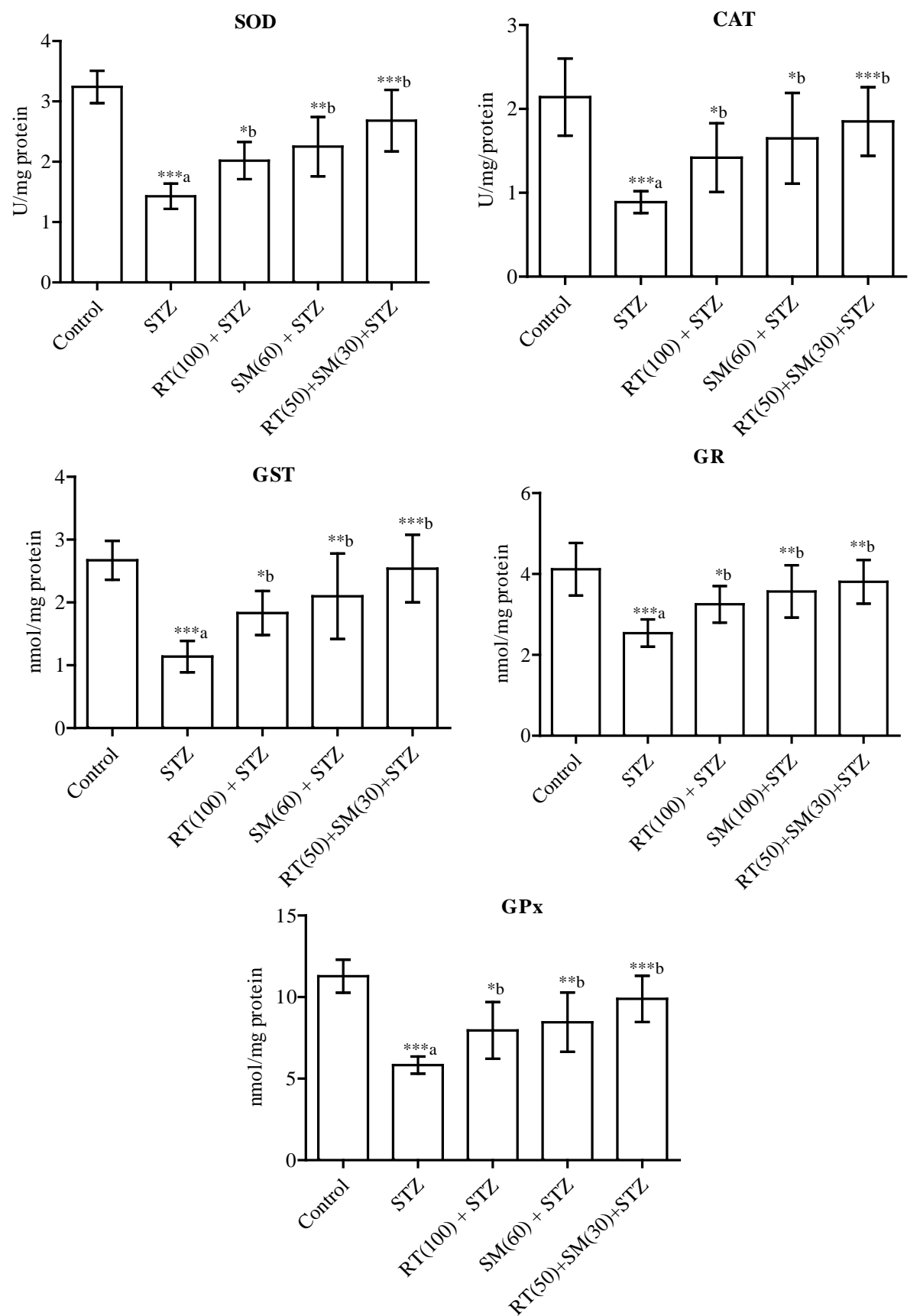

Figure 5. Effect of rutin (RT), silymarin (SM) and their combination on SOD, CAT, GST, GR and GPx activities in sciatic nerve of diabetic and non-diabetic rats. Data expressed as mean \pm SD $(n=6)$. One-way ANOVA and Student-Newman-Keuls multiple comparisons test was applied and the significance levels considered as ${ }^{*} \mathrm{P}<0.05,{ }^{* *} \mathrm{P}<0.01$ and ${ }^{* * *} \mathrm{P}<0.001$. a: significantly different from control group $(\mathrm{P}<0.05)$ and $\mathrm{b}$ : significantly different from STZ group.

increased in diabetic animals compared to controls. It is well known that such inflammatory cytokines play a vital role in systemic inflammation and in propagation of acute phase reaction [49]. Indeed, studies suggested that the elevated values inflammatory mediators during diabetes are a consequence of hyperglycemia and insulin resistance [26] [50]. Treatment with RT or/and SM to the diabetic rats significantly reduced these markers whereas the combined therapy produced higher effect. This may be because of RT and SM has antioxidant and an- 
ti-inflammatory properties [51] [52]. Kwon and his colleagues, [53] reported that, RT ameliorates dextran sulfate sodium-induced experimental colitis in mice by following attenuation of pro-inflammatory gene expressions. Earlier reports documented that SM has anti-inflammatory and analgesic properties [54] [55].

Diabetes mellitus induces oxidative stress by the autoxidation of monosaccharides [56], which leads to production of superoxide and hydroxyl radicals. It is well documented that pain transmission requires production of reactive oxygen species [57]. In present results a significantly higher level of lipid peroxidation marker, MDA, in sciatic nerve of diabetic animals was observed. Glutathione, a potent endogenous antioxidant is a first line of defense against free radicals. The GSH levels were significantly lowered in the sciatic nerve of diabetic animals compared to control group of rats. These observations are in agreement with previous findings showing reduction in GSH levels in diabetes [21] [58]. Intracellular GSH levels have been observed to decrease in brain [34] and sciatic nerve [58] of diabetic animals. The treatments with RT or/and SM significantly reduced lipid peroxidation and regenerated intracellular GSH content in the sciatic nerve; this is probably because of their free radical scavenging activities.

The results of the present study are in agreement with earlier studies wherein decreased SOD and CAT activitieswere observed in nerves isolated from diabetic rats [22]. Reduction in these activities in hyperglycemia might involve non-enzymatic glycosylation [59]. Increased SOD activity after RT or/and SM administration to the diabetic animals is in accordance with reported restoration of SOD activity by rutin in hepatic cells and kindey [52] [60], and SM in serum [61] and liver [62]. CAT is responsible for the catalytic decomposition of $\mathrm{H}_{2} \mathrm{O}_{2}$ to $\mathrm{O}_{2}$ and $\mathrm{H}_{2} \mathrm{O}$. The decreased CAT activity in diabetes might reduce protection against free radicals. It is clear that the simultaneous reduction in the activity of both SOD and CAT makes the sciatic nerve more vulnerable to hyperglycemia-induced oxidative stress. Reports are available wherein RT and SM have been shown to bring about improvement in the CAT activity during diabetic-induced nephrotoxicity in rats [52] [63].

The results obtained emphasize that RT or/and SM protects the sciatic nerve from hyperglycemia induced damage by restoring the activity of both these enzymes. However, the protective results found markedly higher in the combined (RT and SM) group compared to individual groups. GR is an important enzyme involved in maintaining high GSH/GSSG ratios [64]. Present data showed a significant decrease in the activity of GR in sciatic nerve of diabetic animals. The results obtained from the earlier studies also showed depressed GR activity in sciatic nerve [34] and increase and decrease in brain and other organs of diabetic animals [65] [66]. The reversal of GR activity by RT or/and SM treatment might result in increasing intracellular GSH levels. Earlierit has shown that RT and SM protect against the reproductive toxicity effects of cyclophosphamide by increasing GR activity [67]. In present studies, the activity of GPx was found to be significantly depressed in sciatic nerve of diabetic rats and it was reversed by the RT or/and SM treatments. Glutathione reductase is responsible for the regeneration of GSH, whereas GPx and GST work together with GSH in the decomposition of $\mathrm{H}_{2} \mathrm{O}_{2}$ or other organic hydroperoxides. A reduction observed in sciatic nerve GR, GPx and GST activity in diabetic rats might be reflection of decreased protein thiols observed in the study as GSH groups play a critical role in enzyme catalysis [68]. The treatments RT or/and SM ameliorates decrease in the activity of these enzymes which might be mediated by GSH regeneration.

\section{Conclusion}

From the above findings, it has concluded that RT or/and SM has/have the ability to ameliorate diabetic-induced ND via their anti-oxidative and anti-inflammatory properties. The combined therapy of these phenolic compounds is more effective than individual usage particularly in diabetic-induced ND. Thus, combined therapy of $\mathrm{RT}$ and SM is recommendable for diabetic patients against neuropathic pain treatment.

\section{References}

[1] Wild, S., Roglic, G., Green, A., et al. (2004) Global Prevalence of Diabetes: Estimates for the Year 2000 and Projections for 2030. Diabetes Care, 27, 1047-1053. http://dx.doi.org/10.2337/diacare.27.5.1047

[2] Roa, W.I. (2006) Definition and Diagnosis of Diabetes Mellitus and Intermediate Hyperglycemia. WHO Document Production Services, 1-46.

[3] Callaghan, B.C., Little, A.A., Feldman, E.L., et al. (2012) Enhanced Glucose Control for Preventing and Treating Diabetic Neuropathy. Cochrane Database Systematic Review, 6, Article ID: CD007543. http://dx.doi.org/10.1002/14651858.CD007543.pub2 
[4] Abdi, S., Haruo, A. and Bloomstone, J. (2004) Electroconvulsive Therapy for Neuropathic Pain: A Case Report and Literature Review. Pain Physician, 7, 261-263.

[5] Woolf, C.J. (2004) Dissecting out Mechanisms Responsible for Peripheral Neuropathic Pain: Implications for Diagnosis and Therapy. Life Sciences, 74, 2605-2610. http://dx.doi.org/10.1016/j.lfs.2004.01.003

[6] Galer, B.S., Gianas, A. and Jensen, M.P. (2000) Painful Diabetic Polyneuropathy: Epidemiology, Pain Description, and Quality of Life. Diabetes Research and Clinical Practice, 47, 123-128. http://dx.doi.org/10.1016/S0168-8227(99)00112-6

[7] Cameron, N.E., Jack, A.M. and Cotter, M.A. (2001) Effect of Alpha-Lipoic Acid on Vascular Responses and Nociception in Diabetic rats. Free Radical Biology and Medicine, 31, 125-135. http://dx.doi.org/10.1016/S0891-5849(01)00564-0

[8] Stevens, M.J., Obrosova, I., Cao, X., et al. (2000) Effects of DL-Alpha-Lipoic Acid on Peripheral Nerve Conduction, Blood Flow, Energy Metabolism, and Oxidative Stress in Experimental Diabetic Neuropathy. Diabetes, 49, 1006-1015. http://dx.doi.org/10.2337/diabetes.49.6.1006

[9] Calcutt, N.A. (2004) Experimental Models of Painful Diabetic Neuropathy. Journal Neurological Sciences, 220, 137139. http://dx.doi.org/10.1016/j.jns.2004.03.015

[10] Sima, A.A., Zhang, W., Xu, G., et al. (2000) A Comparison of Diabetic Polyneuropathy in Type II Diabetic BBZDR/ Wor Rats and in Type I Diabetic BB/Wor Rats. Diabetologia, 43, 786-793.

[11] Edwards, J.L., Vincent, A.M., Cheng, H.T. and Feldman, E.L. (2008) Diabetic Neuropathy: Mechanisms to Management. Pharmacology \& Therapeutics, 120, 1-34. http://dx.doi.org/10.1016/j.pharmthera.2008.05.005

[12] Figueroa-Romero, C., Sadidi, M. and Feldman, E.L. (2008) Mechanisms of Disease: The Oxidative Stress Theory of Diabetic Neuropathy. Reviews in Endocrine and Metabolic Disorders, 9, 301-314. http://dx.doi.org/10.1007/s11154-008-9104-2

[13] Cameron, N.E. and Cotter, M.A. (1999) Effects of Antioxidants on Nerve and Vascular Dysfunction in Experimental Diabetes. Diabetes Research and Clinical Practice, 45, 137-146. http://dx.doi.org/10.1016/S0168-8227(99)00043-1

[14] Yu, J., Zhang, Y., Sun, S., Shen, J.P., Qiu, J., Yin, X.X., Yin, H.L. and Jiang, S.J. (2006) Inhibitory Effects of Astragaloside IV on Diabetic Peripheral Neuropathy in Rats. Canadian Journal of Physiology and Pharmacology, 84, 579587. http://dx.doi.org/10.1139/y06-015

[15] Arora, M., Kumar, A., Kaundal, R.K. and Sharma, S.S. (2008) Amelioration of Neurological and Biochemical Deficits by Peroxynitrite Decomposition Catalysts in Experimental Diabetic Neuropathy. European Journal of Pharmacology, 596, 77-83. http://dx.doi.org/10.1016/j.ejphar.2008.08.003

[16] Cui, X.P., Li, B.Y., Gao, H.Q., Wei, N., Wang, W.L. and Lu, M. (2008) Effects of Grape Seed Proanthocyanidin Extracts on Peripheral Nerves in Streptozocin-Induced Diabetic Rats. Journal of Nutritional Science and Vitaminology (Tokyo), 54, 321-328.

[17] Cunha, J.M., Jolivalt, C.G., Ramos, K.M., Gregory, J.A., Calcutt, N.A. and Mizisin, A.P. (2008) Elevated Lipid Peroxidation and DNA Oxidation in Nerve from Diabetic Rats: Effects of Aldose Reductase Inhibition, Insulin, and Neurotrophic Factors. Metabolism-Clinical and Experimental, 57, 873-881. http://dx.doi.org/10.1016/j.metabol.2008.01.021

[18] Bierhaus, A., Ziegler, R. and Nawroth, P.P. (1998) Molecular Mechanisms of Diabetic Angiopathy-Clues for Innovative Therapeutic Interventions. Hormone Research, 50, 1-5. http://dx.doi.org/10.1159/000053094

[19] Tuttle, K.R. (2005) Linking Metabolism and Immunology: Diabetic Nephropathy Is an Inflammatory Disease. Journal of the American Society of Nephrology, 16, 1537-1538. http://dx.doi.org/10.1681/ASN.2005040393

[20] Navarro-Gonzalez, J.F. and Mora-Fernandez, C. (2008) The Role of Inflammatory Cytokines in Diabetic Nephropathy. Journal of the American Society of Nephrology, 19, 433-442. http://dx.doi.org/10.1681/ASN.2007091048

[21] Goldberg, R.B. (2009) Cytokine and Cytokine-Like Inflammation Markers, Endothelial Dysfunction, and Imbalanced Coagulation in Development of Diabetes and Its Complications. The Endocrine Society. Journal of Clinical Endocrinology and Metabolism, 94, 3171-3182. http://dx.doi.org/10.1210/jc.2008-2534

[22] Rangkadilok, N., Sitthimonchai, S., Worasuttayangkurn, L., Mahidol, C., Ruchirawat, M. and Satayavivad, J. (2007) Evaluation of Free Radical Scavenging and Antityrosinase Activities of Standardized Longan Fruit Extract. Food and Chemical Toxicology, 45, 328-336. http://dx.doi.org/10.1016/j.fct.2006.08.022

[23] Lopez-Revuelta, A., Sanchez-Gallego, J.I., Hernandez-Hernandez, A., Sánchez-Yagüe, J. and Llanillo, M. (2006) Membrane Cholesterol Contents Influence the Protective Effects of Quercetin and Rutin in Erythrocytes Damaged by Oxidative Stress. Chemico-Biological Interactions, 161, 79-91. http://dx.doi.org/10.1016/j.cbi.2006.03.004

[24] ChoiI, P.Y., Choi, H. and Lee, E.H. (2006) Anti-Adipogenic Activity of Rutin in 3T3-L1 Cells and Mice Fed with High-Fat Diet. BioFactors, 26, 273-281. http://dx.doi.org/10.1002/biof.5520260405 
[25] Nencini, C., Giorgi, G. and Micheli, L. (2007) Protective Effect of Silymarin on Oxidative Stress in Rat Brain. Phytomedicine, 14, 129-135. http://dx.doi.org/10.1016/j.phymed.2006.02.005

[26] Soto, C., Recoba, R., Barrón, H., Alvarez, C. and Favari, L. (2003) Silymarin Increases Antioxidant Enzymes in Alloxan-Induced Diabetes in Rat Pancreas. Comparative Biochemistry and Physiology. Toxicology \& Pharmacology, 136, 205-212.

[27] Ihme, N., Kiesewetter, H., Jung, F., Hoffmann, K.H., Birk, A., Müller, A. and Grützner, K.I. (1996) Leg Oedema Protection from a Buckwheat Herb Tea in Patients with Chronic Venous Insufficiency: A Single-Centre, Randomised, Double-Blind, Placebo-Controlled Clinical Trial. European Journal of Clinical Pharmacology, 50, 443-447. http://dx.doi.org/10.1007/s002280050138

[28] Lindahl, M. and Tagesson, C. (1997) Flavonoids as Phospholipase $A_{2}$ Inhibitors: Importance of Their Structure for Selective Inhibition of Group II Phospholipase $\mathrm{A}_{2}$. Inflammation, 21, 347-356. http://dx.doi.org/10.1023/A:1027306118026

[29] Agarwal, R., Agarwal, C., Ichikawa, H., Singh, R.P. and Aggarwal, B.B. (2006) Anticancer Potential of Silymarin: From Bench to Bed Side. Anticancer Research, 26, 4457-4498.

[30] Polyak, S.J., Morishima, C., Shuhart, M.C., Wang, C.C., Liu, Y. and Lee, D.Y.W. (2007) Inhibition of T-Cell Inflammatory Cytokines, Hepatocyte NF- $\kappa$ B Signaling and HCV Infection by Standardized Silymarin. Gastroenterology, 132, 1925-1936. http://dx.doi.org/10.1053/j.gastro.2007.02.038

[31] Jacobs, B.P., Dennehy, C., Ramirez, G., Sapp, J. and Lawrence, V.A. (2002) Milk Thistle for the Treatment of Liver Disease: A Systematic Review and Meta-Analysis. American Journal of Medicine, 113, 506-515. http://dx.doi.org/10.1016/S0002-9343(02)01244-5

[32] Aleisa, A.M., Abouhashish, H.M., Ahmed, M.M., Al-Rejaie, S.S., Alkhamees, O.A. and Alroujayee, A.S. (2013) Ameliorative Effects of Rutin and Ascorbic Acid Combination on Hypercholesterolemia-Induced Hepatotoxicity in Female Rats. African Journal of Pharmacy and Pharmacology, 7, 280-288. http://dx.doi.org/10.5897/AJPP12.745

[33] Sugimoto, K., Rashid, I.B., Shoji, M., Suda, T. and Yasujima, M. (2008) Early Changes in Insulin Receptor Signaling and Pain Sensation in Streptozotocin-Induced Diabetic Neuropathy in Rats. Journal of Pain, 9, 237-245. http://dx.doi.org/10.1016/j.jpain.2007.10.016

[34] Kamboj, S.S., Vasishta, R.K. and Sandhir, R. (2010) N-Acetylcysteine Inhibits Hyperglycemia-Induced Oxidative Stress and Apoptosis Markers in Diabetic Neuropathy. Journal of Neurochemistry, 112, 77-91. http://dx.doi.org/10.1111/j.1471-4159.2009.06435.x

[35] Sedlak, J. and Lindsay, R.H. (1968) Estimation of Total, Protein-Bound, and Nonprotein Sulfhydryl Groups in Tissue with Ellman's Reagent. Analytical Biochemistry, 25, 192-205. http://dx.doi.org/10.1016/0003-2697(68)90092-4

[36] Kono, Y. (1978) Generation of Superoxide Radical during Autoxidation of Hydroxylamine and an Assay for Superoxide Dismutase. Archives of Biochemistry and Biophysics, 186, 189-195. http://dx.doi.org/10.1016/0003-9861(78)90479-4

[37] Aebi, H. (1974) Catalase. In: Bergmeyer, H.U., Ed., Methods in Enzymatic Analysis, New York, 674-684.

[38] Apfel, S.C., Asbury, A.K., Bril, V., et al. (2001) Positive Neuropathic Sensory Symptoms as Endpoints in Diabetic Neuropathy Trials. Journal of the Neurological Sciences, 189, 3-5. http://dx.doi.org/10.1016/S0022-510X(01)00584-6

[39] Li, F., Drel, V.R., Szabo, C., Stevens, M.J. and Obrosova, I.G. (2005) Low-Dose Poly (ADP-Ribose) Polymerase Inhibitor-Containing Combination Therapies Reverse Early Peripheral Diabetic Neuropathy. Diabetes, 54, 1514-1522.

[40] Obrosova, I.G. (2009) Diabetic Painful and Insensate Neuropathy: Pathogenesis and Potential Treatments. Neurotherapeutics, 6, 638-647. http://dx.doi.org/10.1016/j.nurt.2009.07.004

[41] Romanovsky, D., Hastings, S.L., Stimers, J.R. and Dobretsov, M. (2004) Relevance of Hyperglycemia to Early Mechanical Hyperalgesia in Streptozotocin-Induced Diabetes. Journal of the Peripheral Nervous System, 9, 62-69. http://dx.doi.org/10.1111/j.1085-9489.2004.009204.x

[42] Fuchs, D., Birklein, F., Reeh, P.W. and Sauer, S.K. (2010) Sensitized Peripheral Nociception in Experimental Diabetes of the Rat. Pain, 151, 496-505. http://dx.doi.org/10.1016/j.pain.2010.08.010

[43] Ramirez, M.R., Guterres, L., Dickel, O.E., de Castro, M.R., Henriques, A.T., de Souza, M.M. and Barros, D.M. (2010) Preliminary Studies on the Antinociceptive Activity of Vaccinium ashei Berry in Experimental Animal Models. Journal of Medicinal Food, 13, 336-342. http://dx.doi.org/10.1089/jmf.2009.0079

[44] Lee, J.Y., Jang, Y.W., Kang, H.S., Moon, H., Sim, S.S. and Kim, C.J. (2006) Anti-Inflammatory Action of Phenolic Compounds from Gastrodia elata Root. Archives of Pharmacal Research, 29, 849-858. http://dx.doi.org/10.1007/BF02973905

[45] Al-Enazi, M.M. (2013) Combined Therapy of Rutin and Silymarin Has More Protective Effects on Streptozotocin-Induced Oxidative Stress in Rats. Journal of Applied Pharmaceutical Science, 4, 21-28. 
[46] Prabu, S.M., Shagirtha, K. and Renugadevi, J. (2011) Naringenin in Combination with Vitamins C and E Potentially Protects Oxidative Stress-Mediated Hepatic Injury in Cadmium-Intoxicated Rats. Journal of Nutritional Science and Vitaminology, 57, 177-185. http://dx.doi.org/10.3177/jnsv.57.177

[47] Li, J., Wei, G.H., Huang, H., Lan, Y.P., Liu, B., Liu, H., Zhang, W. and Zuo, Y.X. (2013) Nerve Injury-Related Autoimmunity Activation Leads to Chronic Inflammation and Chronic Neuropathic Pain. Anesthesiology, 118, 416-429. http://dx.doi.org/10.1097/ALN.0b013e31827d4b82

[48] Djordjevic, A., Bursac, B., Velickovic, N., Vasiljević, A. and Matić, G. (2013) The Impact of Different Fructose Loads on Insulin Sensitivity, Inflammation, and PSA-NCAM-Mediated Plasticity in the Hippocampus of Fructose-Fed Male Rats. Nutritional Neuroscience, in press. http://dx.doi.org/10.1179/1476830513Y.0000000098

[49] Locksley, R.M., Killeen, N. and Lenardo, M.J. (2001) The TNF and TNF Receptor Superfamilies: Integrating Mammalian Biology. Cell, 104, 487-501. http://dx.doi.org/10.1016/S0092-8674(01)00237-9

[50] Brownlee, M. (2005) The Pathobiology of Diabetic Complications: A Unifying Mechanism. Diabetes, 54, $1615-1625$. http://dx.doi.org/10.2337/diabetes.54.6.1615

[51] Abu-El-Fattah, A.A., El-Sawalhi, M.M., Rashed, E.R. and El-Ghazaly, M.A. (2010) Possible Role of Vitamin E, Coenzyme Q10 and Rutin in Protection against Cerebral Ischemia/Reperfusion Injury in Irradiated Rats. International Journal of Radiation Biology, 86, 1070-1078. http://dx.doi.org/10.3109/09553002.2010.501844

[52] Alsaif, M.A. (2009) Beneficial Effects of Rutin and Vitamin C Co-Administration in a Streptozotocin-Induced Diabetes Rat Model of Kidney Nephrotoxicity. Pakistan Journal of Nutrition, 8, 745-754. http://dx.doi.org/10.3923/pjn.2009.745.754

[53] Kwon, K.H., Murakami, A., Tanaka, T. and Ohigashi, H. (2005) Dietary Rutin, but Not Its Aglycone Quercetin, Ameliorates Dextran Sulfate Sodium-Induced Experimental Colitis in Mice: Attenuation of Pro-Inflammatory Gene Expression. Biochemical Pharmacology, 69, 395-406. http://dx.doi.org/10.1016/j.bcp.2004.10.015

[54] Ashkavand, Z., Malekinejad, H., Amniattalab, A., Rezaei-Golmisheh, A. and Vishwanath, B.S. (2012) Silymarin Potentiates the Anti-Inflammatory Effects of Celecoxib on Chemically Induced Osteoarthritis in Rats. Phytomedicine, 19, 1200-1205. http://dx.doi.org/10.1016/j.phymed.2012.07.008

[55] Gharagozloo, M., Velardi, E., Bruscoli, S., Agostini, M., Di Sante, M., Donato, V., Amirghofran, Z. and Riccardi, C. (2010) Silymarin Suppress CD4+ T Cell Activation and Proliferation: Effects on NF- $\kappa$ B Activity and IL-2 Production. Pharmacological Research, 61, 405-409. http://dx.doi.org/10.1016/j.phrs.2009.12.017

[56] Bonnefont-Rousselot, D. (2002) Glucose and Reactive Oxygen Species. Current Opinion in Clinical Nutrition \& Metabolic Care, 5, 561-568. http://dx.doi.org/10.1097/00075197-200209000-00016

[57] Viggiano, A., Monda, M., Viggiano, A., Viggiano, D., Viggiano, E., Chiefari, M., Aurilio, C. and De Luca, B. (2005) Trigeminal Pain Transmission Requires Reactive Oxygen Species Production. Brain Research, 1050, $72-78$. http://dx.doi.org/10.1016/j.brainres.2005.05.021

[58] Kuzumoto, Y., Kusunoki, S., Kato, N., Kihara, M. and Low, P.A. (2006) Effect of the Aldose Reductase Inhibitor Fidarestat on Experimental Diabetic Neuropathy in the Rat. Diabetologia, 49, 3085-3093. http://dx.doi.org/10.1007/s00125-006-0400-7

[59] Arai, K., Maguchi, S., Fujii, S., Ishibashi, H., Oikawa, K. and Taniguchi, N. (1987) Glycation and Inactivation of Human Cu-Zn-Superoxide Dismutase. Identification of the in Vitro Glycated Sites. Journal of Biological Chemistry, 262, 16969-16972.

[60] Kamalakkannan, N. and Prince, P.S.M. (2006) Antihyperglycaemic and Antioxidant Effect of Rutin, a Polyphenolic Flavonoid, in Streptozotocin-Induced Diabetic Wistar Rats. Basic \& Clinical Pharmacology \& Toxicology, 98, 97-103. http://dx.doi.org/10.1111/j.1742-7843.2006.pto 241.x

[61] Cecen, E., Dost, T., Culhaci, N., Karul, A., Ergur, B. and Birincioglu, M. (2011) Protective Effects of Silymarin against Doxorubicin-Induced Toxicity. Asian Pacific Journal of Cancer Prevention, 12, 2697-2704.

[62] Jain, A., Yadav, A., Bozhkov, A.I., Padalko, V.I. and Flora, S.J.S. (2011) Therapeutic Efficacy of Silymarin and Naringenin in Reducing Arsenic-Induced Hepatic Damage in Young Rats. Ecotoxicology and Environmental Safety, 74, 607-614. http://dx.doi.org/10.1016/j.ecoenv.2010.08.002

[63] Soto, C., Pérez, J., García, V., Uría, E., Vadillo, M. and Raya, L. (2010) Effect of Silymarin on Kidneys of Rats Suffering from Alloxan-Induced Diabetes Mellitus. Phytomedicine, 17, 1090-1094.

[64] Carlberg, I. and Mannervik, B. (1985) Glutathione Reductase. Methods in Enzymology, 113, 484-490. http://dx.doi.org/10.1016/S0076-6879(85)13062-4

[65] Ulusu, N.N., Sahilli, M., Avci, A., Canbolat, O., Ozansoy, G., Ari, N., et al. (2003) Pentose Phosphate Pathway, Glutathione-Dependent Enzymes and Antioxidant Defense during Oxidative Stress in Diabetic Rodent Brain and Peripheral Organs: Effects of Stobadine and Vitamin E. Neurochemical Research, 28, 815-823.

http://dx.doi.org/10.1023/A:1023202805255 
[66] Sanders, R.A., Rauscher, F.M. and Watkins, J.B. (2001) Effects of Quercetin on Antioxidant Defense in StreptozotocinInduced Diabetic Rats. Journal of Biochemical and Molecular Toxicology, 15, 143-149. http://dx.doi.org/10.1002/jbt.11

[67] Ahmad, I., Shukla, S., Kumar, A., et al. (2012) Biochemical and Molecular Mechanisms of N-Acetyl Cysteine and Silymarin-Mediated Protection against Maneb- and Paraquat-Induced Hepatotoxicity in Rats. Chemico-Biological Interactions, 201, 9-18. http://dx.doi.org/10.1016/j.cbi.2012.10.027

[68] Mak, D.H., Ip, S.P., Li, P.C., Poon, M.K.T. and Ko, K.M. (1996) Alterations in Tissue Glutathione Antioxidant System in Streptozotocin-Induced Diabetic Rats. Molecular and Cellular Biochemistry, 162, 153-158. http://dx.doi.org/10.1007/BF00227543 
Scientific Research Publishing (SCIRP) is one of the largest Open Access journal publishers. It is currently publishing more than 200 open access, online, peer-reviewed journals covering a wide range of academic disciplines. SCIRP serves the worldwide academic communities and contributes to the progress and application of science with its publication.

Other selected journals from SCIRP are listed as below. Submit your manuscript to us via either submit@scirp.org or Online Submission Portal.
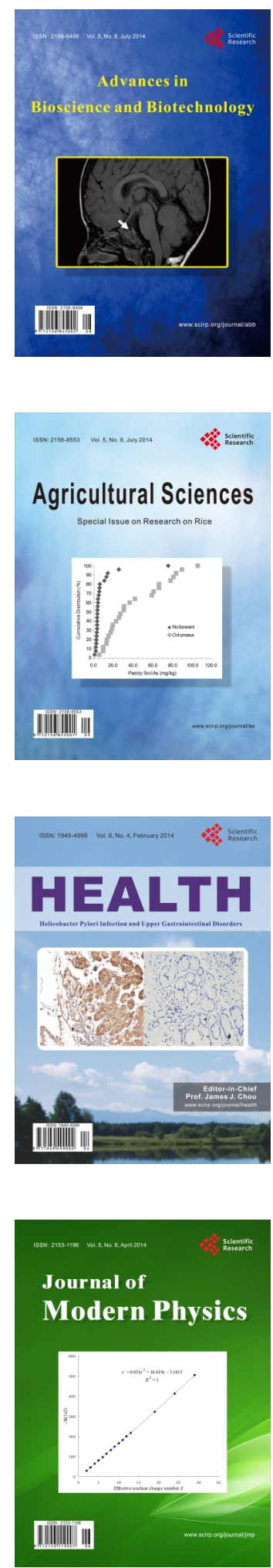
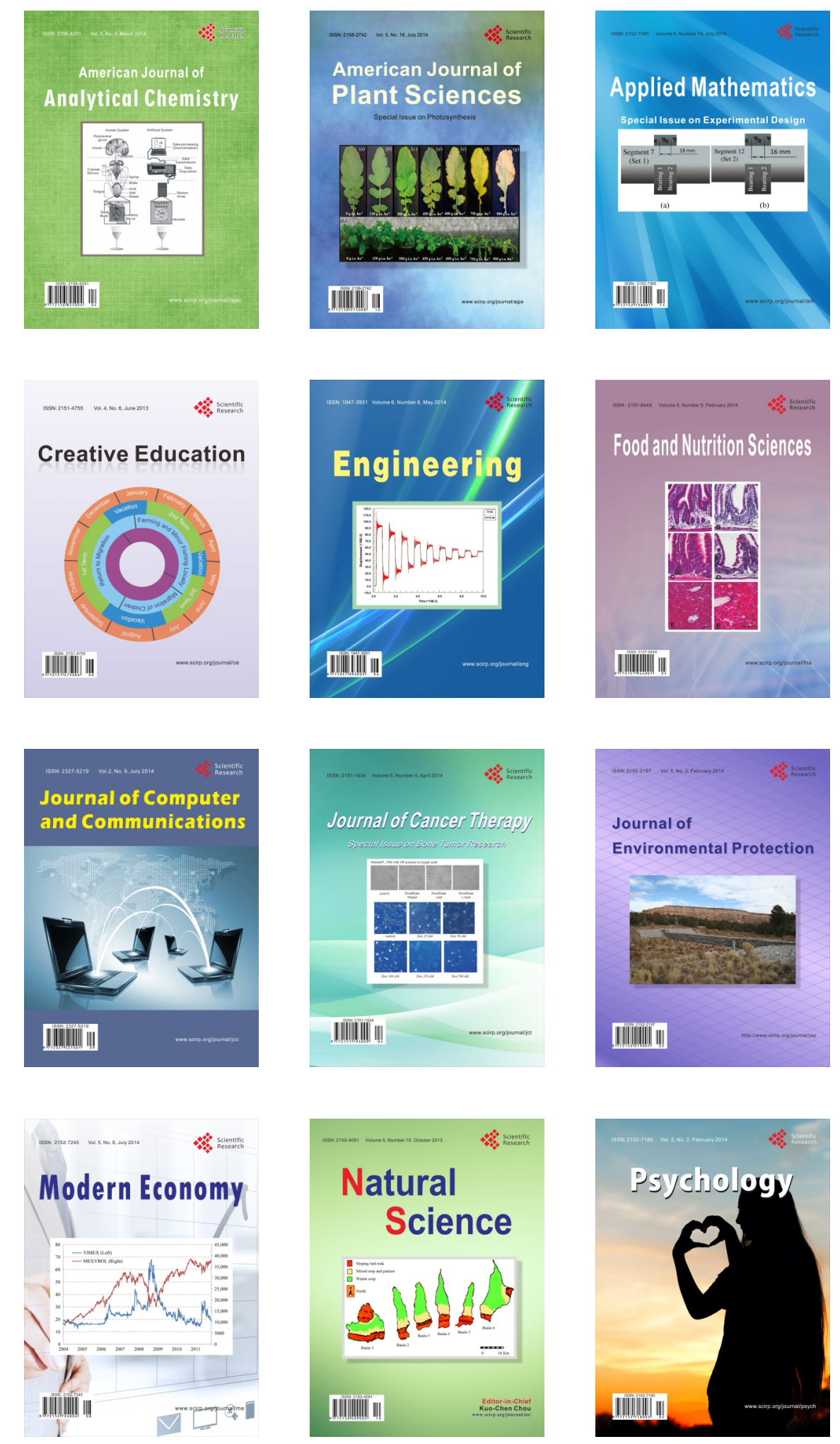